
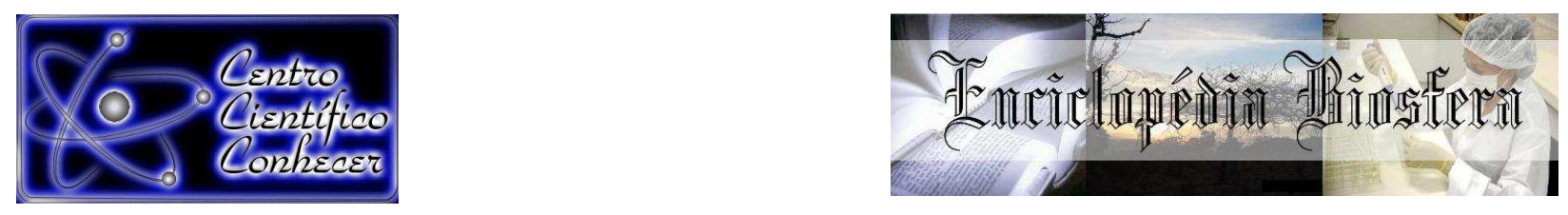

\title{
EXTRAÇÃO DE TANINO CONDENSADO DA CASCA DO CAFÉ CONILON E USO DESTE COMO COAGULANTE PARA REMOÇÃO DE TURBIDEZ DA ÁGUA
}

\footnotetext{
Túlio Dias de Almeida', Breno Frigini mai², Flávia Pereira Puget ${ }^{3}$

${ }^{1}$ Estudante do Curso de Engenharia Química das Faculdades Integradas de Aracruz (E-mail:tuliodyaz@hotmail.com) Aracruz/Es-Brasil

${ }^{2}$ Egresso do Curso de Engenharia Química das Faculdades Integradas de Aracruz

${ }^{3}$ Professora Doutora do Curso de Engenharia Química das Faculdades Integradas de Aracruz
}

\section{Recebido em: 08/04/2016 - Aprovado em: 30/05/2016 - Publicado em: 20/06/2016 DOI: 10.18677/Enciclopedia_Biosfera_2016_148}

\begin{abstract}
RESUMO
No Brasil, o alto consumo de café tem gerado grande quantidade de cascas obtidas durante o processamento desse grão. Dentre as substâncias comumente presentes na casca do café estão os taninos, que são compostos fenólicos facilmente oxidáveis e que vem sendo amplamente utilizado na estabilização da cerveja, como coagulante no tratamento de efluentes, etc. $O$ presente trabalho visou 0 reaproveitamento da casca do café conilon (Caffea canephora) para a extração de proantocianidinas e avaliar a sua utilização como coagulante no tratamento de água. A água foi utilizada como o solvente na etapa de extração e seguiu a metodologia apresentada por TRUGUILHO et al. (2003) para quantificar o tanino. O ensaio de coagulação foi realizado em JarTest, usando uma solução contendo $1 \mathrm{~g}$ do tanino extraído dissolvido em ácido clorídrico a $1 \%(\mathrm{~m} / \mathrm{v})$ como coagulante. Duas amostras de água da lagoa Modenesi-ES com turbidez de 23,60 uT (amostra I) e 21,30 uT (amostra II) foram avaliadas nos ensaios. Os resultados obtidos mostraram que o percentual de tanino obtido a partir da casca do café conilon não foi alto $(8,4 \%)$, quando comparado a outras fontes, mas em virtude da grande disponibilidade da matéria prima, a casca se mostra como uma alternativa atrativa. Ao utilizar o tanino condensado extraído como coagulante observou-se que o mesmo não se mostrou eficiente para as condições testadas.
\end{abstract}

PALAVRAS-CHAVE: casca de café, ensaio de coagulação, taninos condensados

\section{EXTRACTION OF CONDENSED TANNIN FROM CONILON COFFEE HUSKS AND USE OF THE TANNIN AS COAGULANT IN WATER TURBIDITY REMOVAL}

\begin{abstract}
In Brazil, high consumption of coffee has generated lot of shells obtained during the processing of the grain. Among the commonly occurring substances in the coffee husks are tannins, which are phenolic compounds easily oxidized and has been widely used in beer stabilization, as a coagulant in wastewater treatment, etc. This work aimed at the reuse of husks from conilon coffee (Caffea canephora) for proanthocyanidin extraction and evaluate its use as a coagulant in water treatment. Water was used as the solvent in the extraction step and was followed the methodology presented by TRUGUILHO et al. (2003) to quantitate the tannin. The
\end{abstract}


clotting assay was performed in JarTest using a solution containing $1 \mathrm{~g}$ of the extracted tannin dissolved in hydrochloric acid $1 \%(\mathrm{w} / \mathrm{v})$ as the coagulant. Two samples of water from Modenesi-ES pond with turbidity of $23.60 \mathrm{NTU}$ (sample I) and 21.30 NTU (sample II) were evaluated in the trials. The results showed that the percentage of tannin obtained from the conilon coffee husks was not high $(8.4 \%)$ when compared to other sources, but because of the large availability of the raw materials, the husk is shown as an attractive alternative. By using the condensed tannin extracted as coagulant was observed that it was not efficient for the conditions tested.

KEYWORDS: condensed tannins, coffee husks, coagulation test

\section{INTRODUÇÃO}

No ano de 2015 o Brasil produziu 43,24 milhões de sacas de café beneficiado, garantindo o primeiro lugar como maior produtor e exportador mundial de café (MAPA, 2015). Desse total, 11,19 milhões de sacas foram de café conilon, ocupando uma área plantada de 472,6 mil hectares (CONAB, 2015), gerando em torno de 11 milhões de toneladas de sacas de $60 \mathrm{~kg}$.

Principal resíduo do processamento do café, a casca tem sido objeto de estudo por vários autores, como por exemplo, a sua utilização na dieta para vacas em lactação (ROCHA et al., 2006), na germinação e crescimento de pepino (MAY et al., 2011) e para avaliação do seu teor nutritivo (LEITÃO et al., 2005). Dentre as várias substâncias presentes na casca do café, estes autores confirmaram a presença do tanino, composto que garante o sabor adstringente do café.

De acordo com MONTEIRO et al. (2005), taninos são compostos fenólicos facilmente oxidáveis que podem ser identificados através de precipitação com gelatinas e são classificados em hidrolisáveis e condensados de acordo com sua estrutura química. Os taninos condensados, também conhecidos como proantocianidinas, são polímeros de flavan-3-ol oriundos do metabolismo do fenilpropanol. Segundo ASHOK \& UPADHYAYA (2012), os mesmos são ligados por pontes de carbono e são solúveis em água. $O$ autor diz ainda que taninos hidrolisáveis, podem ser subdivididos em dois grupos, os galotaninos e os elagitaninos de acordo com a esterificação dos grupos hidroxila. Quando submetidos a reações com ácidos ou bases fracas os taninos hidrolisáveis sofrem hidrólise produzindo carboidratos e ácidos fenólicos.

Segundo PAES et al. (2006), tanto os taninos hidrolisáveis quanto os condensados podem ser encontrados em diferentes partes das plantas, como no cerne, cascas, frutos e sementes, de acordo com). Dependendo do tipo de planta ou da parte da planta estudada os taninos podem ser encontrados em diferentes quantidades, como relatou PANSERA et al. (2003). Os autores fizeram uma análise de taninos totais em plantas aromáticas e medicinais e constatou que, nas 8 espécies estudadas, o percentual de taninos variou de 0,01 a 18,90\%.

Avaliando o teor de proantocianidinas em 12 frutas nativas do cerrado, ROCHA et al. (2011) encontraram que o teor de proantocianidinas variou entre $4 \mathrm{e}$ $291 \mathrm{mg} / 100 \mathrm{mg}$ de polpa analisada para ambas as espécies $E$. dysenterica e $E$. calcyna. ASHOK \& UPADHYAYA (2012) dizem que dependendo da região e da idade da planta a estrutura dos taninos pode variar. Os autores também ressaltam que o tanino reduz a palatabilidade em folhas de plantas, como as da sempre-viva, protegendo-as contra predadores. Dependendo da parte da planta estudada, tanto o teor de proantocianidinas quanto o teor de taninos hidrolisáveis pode variar, segundo 
BERNARDES et al. (2011), que analisaram o teor de proantocianidinas na casca e no fruto da aroeira e encontraram que o teor variou de 2,54 a $2,70 \%$, enquanto que não foram detectados taninos hidrolisáveis por esses serem mais comumente encontrados nas copas das árvores dessas espécies.

Os taninos vêm sendo amplamente empregados na indústria. BATTESTIN et al. (2004) discutem a importância industrial dos taninos na estabilização da cerveja, onde se usa o tanino hidrolisável para reduzir a concentração protéica da mesma. Também destaca que os taninos são utilizados no curtimento de pele animal, na produção de resinas, e como agente floculante no tratamento de água. Fazendo um estudo do lixiviado do aterro sanitário de Maringá-PR, PEDROSO et al. (2012) utilizaram o Tanfloc $\mathrm{SG}^{\circledR}$ proveniente da acácia-negra. Os autores avaliaram parâmetros como cor, turbidez e compostos absorvidos e chegaram a conclusão que o coagulante apresentou resultados satisfatórios. O seu uso no tratamento de água vem sendo estudado por diversos autores, como por exemplo, SKORONSKI et al. (2014), que estudaram a aplicação do tanino como agente floculante alternativo ao sulfato de alumínio, no tratamento da água do rio Tubarão em Santa Catarina. BONGIOVANI et al. (2010) também estudaram os benefícios de se usar o Tanfloc $S S^{\circledR}$, coagulante natural a base de tanino, para obtenção de água potável. Os autores concluiram que o uso de coagulantes orgânicos como o tanino possui benefícios de saúde pública e preservação ambiental quando comparado a coagulantes convencionais.

Visando usar um coagulante natural e ao mesmo tempo dar uma destinação correta às cascas provenientes do processamento do café, o objetivo deste trabalho foi avaliar o potencial tanífero das cascas do Caffea canephora e testar o seu uso como agente coagulante para o tratamento da água, utilizando a lagoa Modenesi, situada no município de Aracruz-ES como estudo de caso.

\section{MATERIAL E MÉTODOS}

\section{Preparação do Material}

As cascas do café conilon utilizadas para a extração do tanino a ser utilizado no experimento foram coletadas em uma propriedade do norte do Espírito Santo. Coletou-se $1 \mathrm{~kg}$ de cascas secas que foram armazenadas no Laboratório de Química II da FAACZ, Vicente Gentil. As cacas foram secas em estufa a $60{ }^{\circ} \mathrm{C}$ até atingir um percentual mássico de umidade de $15 \%$.

Para a realização dos ensaios de coagulação foram coletadas duas amostras de água da lagoa Modenesi, situada em Aracruz-ES. As amostras foram armazenadas em duas bombonas plásticas (22 litros cada) e alojadas em ambiente ventilado durante o tempo de estudo. Duas amostras, uma de cada bombona, foram retiradas para análise e apresentaram turbidez de 23,60 uT (amostra I) e 21,30 uT (amostra II).

\section{Extração do Tanino}

Para avaliar o teor de proantocianidinas na casca Caffeacanephora, foram feitos ensaios de extração com base no trabalho apresentado por PAES et al. (2006). Foi utilizado um extrator do tipo Soxhlet e realizou-se os ensaios de extração em triplicata. Em um balão de destilação de $500 \mathrm{~mL}$ foram colocados água, que foi o agente extrator, e $10 \mathrm{~g}$ de cascas secas numa relação água/casca de 25:1. Os tempos de extração variaram de 1, 2, 4 e 6 horas a fim de verificar em que tempo 
poderia ser obtido a maior quantidade de tanino. Um esquema do aparato montado pode ser visto na Figura 1.

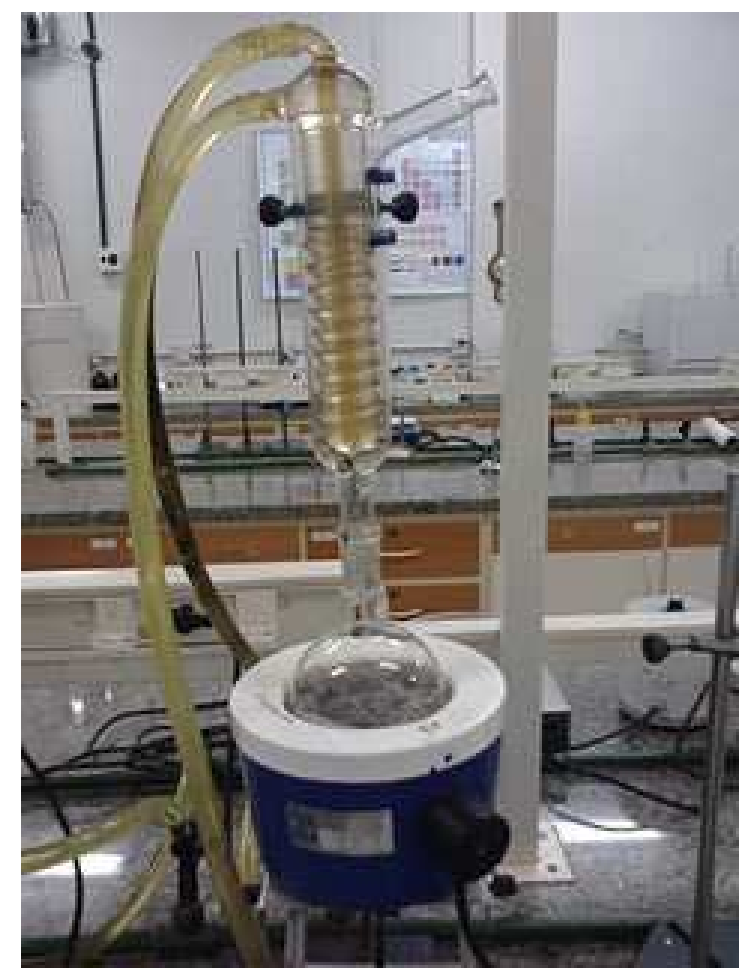

FIGURA 1: Aparato experimental usado na extração do tanino.

Fonte: Acervo dos autores.

O extrato obtido foi deixado em estufa a $60{ }^{\circ} \mathrm{C}$ até massa constante. A $100 \mathrm{~mL}$ desse mesmo extrato adicionou-se $10 \mathrm{~mL}$ de aldeído fórmico e $5 \mathrm{~mL}$ de $\mathrm{HCL}$ concentrado e deixou-se descansar em estufa por 24 horas, seguindo a metodologia proposta por TRUGUILHO et al. (2003) que diz que sob essas condições é possível recuperar por filtração os taninos condensados, que após recuperação foram secos a $60{ }^{\circ} \mathrm{C}$ até massa constante.

O teor de extrativos totais (TET-\%) ,o Teor de Taninos Condensados no Extrato (TTCE-\%) e o Teor de taninos Condensados na Casca (TTC-\%) foram calculados usando as equações apresentadas por TRUGUILHO et al. (2003). O Índice de Stiansy (IS-\%) foi calculado empregando a equação usada por Paes et al. (2006).

Os ensaios de coagulação foram realizados em Jar Test, modelo JT-102 da marca Milan ${ }^{\circledR}$, composto por 6 cubas de capacidade de 2 L. Inicialmente, adicionouse $1 \mathrm{~L}$ de água da amostra I em cada cuba do reator. Logo após, acrescentou-se o coagulante e os jarros foram submetidos à agitação de $120 \mathrm{rpm}$ por $2 \mathrm{~min}, 50 \mathrm{rpm}$ por $15 \mathrm{~min}$ e $10 \mathrm{~min}$ de repouso simulando mistura rápida, mistura lenta e decantação, respectivamente. Os intervalos das concentrações de tanino testadas variaram de 0,2 a 1,2 ppm; 1 a 6 ppm e 7 a 12 ppm, com variações de 0,2 ppm para o primeiro intervalo testado e variações de $1 \mathrm{ppm}$ para os outros dois intervalos. A solução de tanino usada foi preparada adicionando $1 \mathrm{~g}$ do tanino extraído a uma solução $1 \%$ de ácido clorídrico a $1 \%(\mathrm{~m} / \mathrm{v})$. 


\section{RESULTADOS E DISCUSSÕES}

Os resultados apresentados na Tabela 1 permitem observar que para os tempos de 4 e 6 horas de extração, a quantidade de taninos condensados (TTC) extraída praticamente dobra quando comparada aos tempos de uma e duas horas.

TABELA 1- Análise estatística descritiva do teor de taninos na casca do Caffea canephora

\begin{tabular}{cccccc}
\hline $\begin{array}{c}\text { Tempo } \\
(\mathrm{h})\end{array}$ & TTC $(\%)$ & Média & Erro padrão & $\begin{array}{c}\text { Desvio } \\
\text { padrão }\end{array}$ & $\begin{array}{c}\text { Variância da } \\
\text { amostra }\end{array}$ \\
\hline $1^{*}$ & $4,16 \pm 0,18$ & 4,30 & 0,14 & 0,20 & 0,040 \\
$2^{*}$ & $4,44 \pm 0,39$ & & & & \\
\hline \hline $4^{* *}$ & $8,40 \pm 0,44$ & 8,45 & 0,04 & 0,06 & 0,004 \\
$6^{* *}$ & $8,49 \pm 0,23$ & & & & \\
\hline
\end{tabular}

${ }^{\star}$ Nível de confiança $(95 \%)=1,78 ;{ }^{* \star N}$ Nível de confiança $(95 \%)=0,57$.

A análise estatística dos dados ainda permitem verificar que não é conveniente extrair taninos no tempo de 6 horas, uma vez que entre os tempos de 4 e 6 , que apresentou um desvio padrão igual a 0,06 , mostra que o teor de taninos extraído nestes tempos são estatisticamente semelhantes. Dessa forma, o tempo de 4 horas pode ser considerado o melhor, com TTC de $8,40 \%$, correspondendo a $0,34 \mathrm{~g}$ de taninos $/ 10 \mathrm{~g}$ de casca.

Vale ressaltar ainda que, a quantidade de tanino extraída é baixa quando comparada com outras espécies produtoras de tanino. LIMA et al. (2014) avaliaram o teor de taninos condensados do angico, jurema-preta e jurema-vermelha e encontraram teores de 11,89, 17,74 e 18,11\% respectivamente, usando água destilada como solvente. Avaliando o potencial tanífero em espécies de angico provenientes de localidades diferentes, (Viçosa e Canaã, municípios de Minas Gerais-MG), ANDRADE et al. (2013) encontraram teores de 13,30\% e 13,49\% para os municípios de Viçosa e Canaã, respectivamente, usando água como solvente para a extração. Com o intuito de avaliar adesivos à base de taninos da Pinus caribaea var. bahamensis e de Acacia mearnsii, CARVALHO et al. (2014) encontraram um teor máximo de 29,9 \% quando usou uma solução de água mais $10 \%$ de sulfito de sódio como solventes para a extração. A diferença de teores encontrada pelos autores está relacionada com a diferença de idade das plantas, ao tipo de extração, dentre outros fatores (ANDRADE et al., 2013). Para o tanino extraído, em virtude da fácil aquisição da matéria prima e considerando que é possível produzir $34 \mathrm{~g}$ taninos $/ \mathrm{kg}$ de casca e que de acordo com o MAPA (2015), em 2015 o Brasil produziu 43,24 milhões de sacas de café, a extração de tanino tornase atrativa pois, durante 0 processamento gera-se de casca quase a mesma quantidade de café beneficiado.

Quando testado como coagulante, o tanino não se mostrou eficiente para as condições testadas, pois não foi observada coagulação. Possivelmente a baixa turbidez das amostras coletadas e as faixas de coagulante testadas podem ter levado ao insucesso dos ensaios, já que BONGIOVANI et al. (2010) utilizaram uma amostra com turbidez de 82 UT e encontraram a melhor remoção de turbidez quando a concentração de tanino foi de aproximadamente $20 \mathrm{ppm}$. Analisando o tratamento de água pluviais com uma turbidez de 35,8 uT, MARTINI \& MORUZZI 
(2013) conseguiram os melhores resultados para a faixa de coagulação entre 15 ppm e 37,5 ppm.

\section{CONCLUSÃO}

O melhor tempo de extração de taninos, usando o procedimento experimental adotado, foi o de 4 horas, com um percentual de extração de 8,40\%. Quando usado como coagulante, o tanino extraído da casca do Caffeacanephora não foi eficiente para as condições testadas, já que não foi observada coagulação. Sugere-se avaliar outras faixas de concentração do coagulante e o uso de amostras com turbidez inicial mais altas.

\section{REFERÊNCIAS}

ANDRADE, B.G. CARNEIRO, A. de C.O.; VITAL, B.R.; SOUZA, de A. L.; COELHO, D.J. da S. Determinação do potencial tanífero em povoamentos de angico. Ciência da Madeira (Braz. J. Wood Sci.), Pelotas, v.04, n.02, p. 139-151, Novembro de 2013. Disponível em: <https://periodicos.ufpel.edu.br/ojs2/index.php/cienciadamadeira/article/view/4059/32 03>.Doi: 10.12953/2177-6830.v04n02a02.

ASHOK, P.K.; UPADHYAYA, K. Tannins are astringent. Journal of farmacognosy and phytochemistry, v.1, n.3, 2012.

BATTESTIN, V.; MATSUDA, L.K.; MACEDO, G.A. Fontes e aplicações de taninos e tanases em alimentos. Alim. Nutr., Araraquara, v.15, n.1, p.63-72, 2004.

BERNARDES, N.R.; GLÓRIA, L.L.; NUNES, C.R.; PESSANHA, F.F.; MUZITANO, M.F.; OLIVEIRA. de D.B. Quantificação dos teores de taninos e fenois totais e avaliação da atividade antioxidante dos frutos da aroeira. Vértices, Campos dos Goytacazes/RJ, v.13, n.3, p.117-128, Set./Dez., 2011.

BONGIOVANI, M.C.; MORAES, L.C.K.; BERGAMASCO, R.; LOURENÇO, B.S.S.; TAVARES, C.R.G. Os benefícios da utilização de coagulantes naturais para a obtenção de água potável. Acta Scientiarum. Technology, Maringá, v.32, n.2 p.167170 , 2010

Disponível

em: http://periodicos.uem.br/ojs/index.php/ActaSciTechnol/article/view/8238/8238 DOI: 10.4025/actascitechnol.v32i2.8238.

BRASIL. MINISTÉRIO DA AGRICULTURA, PECUÁRIA E ABASTECIMENTO. CAFÉ. BRASÍLIA/DF. Acessado em 01/04/2016 às 14h:20 min.

CARVALHO, A.G.; LELIS, R.C.C.; NASCIMENTO, do A.M. AVALIAÇÃO DE ADESIVOS À BASE DE TANINOS DE Pinus caribaea var. bahamensis e de Acacia mearnsii NA FABRICAÇÃO DE PAINÉIS AGLOMERADOS. Ciência Florestal, Santa Maria, v.24, n.2, p.479-489, abr.-jun., 2014. Disponível em: http://dx.doi.org/10.5902/1980509814588. Doi: 10.5902/1980509814588.

COMPANHIA NACIONAL DE ABASTECIMENTO. ACOMPANHAMENTO DA SAFRA BRASILEIRA DE CAFÉ, v.2 - Safra 2016, n.1 - Primeiro Levantamento, 
Brasília, p.1-68, jan. 2016.

LEITÃO, R.A.; PAIVA, de P.C.A.; REZENDE, DE C.A.P. Valor nutritivo da casca do café (Coffea arabica L.) tratada com hidróxido de sódio e/ou uréia suplementada com feno de alfafa (Medicago sativa L.). Pesquisa agropecuária tropical, 35 (1): 31-36, $2005 . \quad$ Disponível https://doaj.org/article/86edb81c964a472b81c39cd48e137a74. em: 10.5216/pat.v35i1.2283.

LIMA, de C.R.; PAES, J.B.; LIMA, de V. L. A.; DELGADO, M.F.F.; LIMA, R.A. Potencialidade dos extratos tânicos de três espécies florestais no curtimento de peles caprinas. Revista brasileira de Engenharia Agrícola e Ambiental, v.18, n.11, p.1992-1997, 2014.Disponível em: http://dx.doi.org/10.1590/18071929/agriambi.v18n11p1192-1197. Doi: 10.1590/1807-1929/agriambi.v18n11p11921197.

Martini, M. V. P de; Moruzzi, R. B. Tratabilidade de águas pluviais utilizando coagulante natural a base de tanino visando fins não potáveis. Teoria e Prática na Engenharia Civil, v.13, n.22, p. 15-23, 2013.

MAY, D.; OLIVEIRA, de C.M.R.; ROCHA, L.D.; MARANHO, L.T. E. Efeitos de extratos de casca de café (Coffea arabica L.) na germinação e crescimento de pepino(cucumis sativus L.). Brazilian Journal of Biosciences, Porto Alegre, v.9, n.2, p-180-186, abr./jun.2011. Disponível em: http://www.ufrgs.br/seerbio/ojs/index.php/rbb/article/view/1712.

MONTEIRO, J.M.; ALBUQUERQUE, de U.P.; ARAÚJO, E. de L.; AMORIM, de E.L.C.Taninos: uma abordagem da química à ecologia, Quim. Nova, v.28, n.5, 892896, 2005. Disponível em: http://dx.doi.org/10.1590/S0100-40422005000500029. Doi: 10.1590/S0100-40422005000500029.

PAES, J.B.; DINIZ, C.E.F.; MARINHO, I.V.; LIMA, de C.R. Avaliação do potencial tanífero de seis espécies florestais de ocorrência no semi-árido brasileiro. Cerne, Lavras, v.12, n.3, p 232-238, jul./set. 2006.

PANSERA, M.R.; SANTOS, A.C.A.;PAESE, K.;WASUM, R.; ROSSATO, M.; ROTA, L.D.; PAULETTI, G.F.; SERAFINI, L.A. Análise de taninos totais em plantas aromáticas e medicinais cultivadas no Nordeste do Rio Grande do Sul. Revista brasileira de farmacognosia, V.13, n.1, p 17-22, jan. /jun. 2003.

PEDROSO, K.; TAVARES, C.R.G.; JANEIRO, V.; SILVA, da T.L.; DIAS, P.Z. Avaliação do tratamento do lixiviado do aterro sanitário de Maringá, Paraná, por processo de coagulação/floculação com Tanfloc $S G^{\circledR}$. Revista de Engenharia e Tecnologia, v.4, n.2, Ago/2012.

ROCHA, W.S.; LOPES, R.M.; SILVA, da D.B.; VIEIRA, R.F.; SILVA, da J. P.; COSTA, T. da S. A. Compostos fenólicos totais e taninos condensados em frutas nativas do cerrado. Rev. Bras. Frutic., Jaboticabal-SP, v.33, n.4, p 1215-1221, Dezembro 2011. 
ROCHA,F.C.; GARCIA, R.; PAULO FREITAS, de A. W.;SOUZA, de A. L.; GOBBY, K. F.; FILHO, S. de .C.V.; TONUCCI, R.G.; ROCHA, G.C. Casca de café em dietas para vacas em lactação: consumo, digestibilidade, produção e composição de leite. Revista Brasileira de Zootecnia, v.35, n.5, p.21632171, 2006. Disponível em: http://www.scielo.br/scielo.php?script=sci_arttext\&pid=S1516-35982006000700037. Doi: 10.1590/S1516-35982006000700037.

SHORONSKI, E.; NIERO, B.; FERNANDES, M.; ALVES, M.V.; TRAVISAN, V. Estudo da aplicação de tanino no tratamento de água para abastecimento captada no rio Tubarão, na cidade de Tubarão, SC. Rev. Ambient.Água, vol.9, n.4, Taubaté, Out. /Dez. 2014. Disponível em: http://dx.doi.org/10.4136/ambi-agua.1303. Doi: 10.4136/ambi-agua.1303.

TRUGUILHO, P.F.; MORI, F.A.; LIMA, J.T.; CARDOSO, D. P. Determinação do teor de taninos na casca de Eucalyptus spp. Cerne, Lavras, v.9, n.2, p. 246-254, jul./dez. 2003. 